\title{
Optimization of individual elements of clonal micro-propagation of fruit and berry crops in the production system of healthy planting material
}

\author{
L. V. Tashmatova*, O.V. Matsneva, T. M. Khromova, and $V$. V. Shakhov \\ FSBSI All-Russian Research Institute of Fruit Crop Breeding, Oryol region, Russia
}

\begin{abstract}
Clonal micro-propagation is of particular importance in the transition to virus-free gardening. The problems of in vitro cultivation are closely related to mineral nutrition, presence of growth hormones and varietal features of plants. The purpose of the research was to study the patterns of responses of the studied genotypes of fruit and berry crops to the effect of various nutrient media. The objects of the study were varieties of garden strawberries, blackberries, pears and apple trees. Single shoots were planted on a modified medium of MS, Boxus, QL, B5, Pierik, Ly de Fossard, Fardzinova. The number of developed buds per explant, the height of micro-shoots, the general appearance and development of microplants were taken into account. It was found that exclusion of ammonium nitrate $(\mathrm{NH} 4 \mathrm{NO} 3)$ and replacement of calcium chloride $(\mathrm{CaCl} 2)$ with calcium nitrate $(\mathrm{Ca}(\mathrm{NO} 3) 2)$ in the Boxus nutrient medium in strawberry provided obtaining optimally developed plants. For blackberries, the best results of proliferation and growth of shoots were obtained on the growing medium of Ly de Fossard, in pear varieties - on the Ly de Fossard medium. For most of the studied apple tree varieties, the most favorable medium was QL, containing $2.0 \mathrm{mg} / 1$ of 6-BAP.
\end{abstract}

\section{Introduction}

One of the most effective ways to increase fruit and berry crops yield is the introduction of healthy planting material into production [1]. Vegetatively propagated fruit and berry crops are strongly affected by viral and mycoplasma diseases, leading to productivity loss, decrease in winter hardiness and adaptive properties of the planting material [2-4]. The transition to virus-free gardening in recent years is of particular importance, when there is a massive spread in plantings of viral infections, increasing the predisposition of plants to be affected by other phytopathogens $[5,6]$. Modern studies show that plants obtained in vitro are characterized by genotypic uniformity, high viability, adaptability and productivity in comparison with those propagated vegetatively [7,8]. The technology of clonal micropropagation is currently widely used in science and practice. At the same time, the elements

\footnotetext{
${ }^{*}$ Corresponding author: tashmatova@vniispk.ru
} 
of micro-propagation are improved and optimized: sterilization schemes during culture initiation, nutrient media for obtaining the maximum number of regenerants during in vitro reproduction and rooting, and adaptation schemes to ex vitro conditions. Nutrition problems overlap with cultivation problems, which reduces the efficiency of micro-propagation and increases the cost of the resulting material. In recent years, the assortment of fruit and berry crops has been supplemented with a significant number of highly productive commercial varieties that require in vitro study and improvement of technology, taking into account genotypic features [9-12]. Varietal features of plants affect not only the need for various biologically active substances, but also the elements of mineral nutrition in isolated culture; that is why the micro-propagation success is largely determined by correct choice of nutrient medium [13]. A detailed study of regeneration issues makes it possible to use this process for accelerated reproduction and obtaining healthy planting material.

The purpose of the present research was to study the responses patterns of the studied genotypes of fruit and berry crops to the action of various nutrient media.

\section{Materials and methods}

The objects of research were varieties of garden strawberry Honey (Honeyoye), Marmolada, Tsaritsa, Bereginya, Urozhaynaya CGL, Korona; blackberry - Thornfree (Thorn free), Agawam, Eri, Black Satin seedling; pear varieties - Tyutchevskaya, Lada, Orlovskaya Letnyaya, Annushka; apple tree varieties - Bolotovskoye, Imrus, Kandil Orlovsky, Orlovskoe Polesie, Veteran.

The studies were conducted in accordance with the methodological recommendations of O.V. Matushkina and co-authors [14], E. N. Dzhigadlo with co-authors [15], scientific research of N.V. Kukharchik and co-authors [13].

At the micro-propagation stage, explants planted on artificial growing media were single micro-plants taken from the passaged culture in vitro. For strawberry, a modified Murashige-Skoog (MS) [16] growing medium with a concentration of 6-benzylaminopurine (6-BAP) of $0.5 \mathrm{mg} / \mathrm{l}$ and an alternation of a hormone-free growing medium MS with a Boxus growing medium [17] (6-BAP - $1.0 \mathrm{mg} / \mathrm{l})$ were used. For blackberries, the media MS, Ly de Fossard [18], Gamborg (B5) [19] were used; for pears - MS, B5, Ly de Fossard, Pierik [20]; for apple trees - Quoirin-Lepoivre (QL) [21]; and Fardzinova. Fardzinova medium, developed for pears, contains half the composition of the macrosalts of the MS growing medium and the $\mathrm{ZnSO}_{4} \times 7 \mathrm{H}_{2} \mathrm{O}$ microsalt, and an additional growth stimulator, lemongrass tincture (30 drops/1). Growing media were enriched with vitamins $\mathrm{C}-1.0-1.5$ $\mathrm{mg} / \mathrm{l}, \mathrm{B}_{1}, \mathrm{~B}_{6}, \mathrm{PP}-0.5 \mathrm{mg} / \mathrm{l}$ each. To reduce leaf chlorosis, the concentration of iron chelate in growing media was increased by 3-4 times. The counts were carried out after 4 weeks of cultivation. During four passages, the resulting microplants conglomerates were divided one by one and again subcultivated on the studied nutrient media. The number of developed buds per explant, the height of micro-shoots, the general appearance and development of micro-plants were considered.

Statistical processing of the research results was carried out using Microsoft Excel (2016) computer program.

\section{Results and discussions}

\subsection{Strawberry}

In the course of the studies, the morphological characteristics of regenerating plants grown on the alternation of the hormone-free Murashige-Skoog growing medium and the Boxus 
growing medium with a content of 6-BAP $1.0 \mathrm{mg} / \mathrm{l}$ were evaluated. As a control, regenerating plants were used on a basal MS growing medium with a 6-BAP concentration $0.5 \mathrm{mg} / \mathrm{l}$. The results of studies on the influence of the growing medium composition on the proliferative activity of strawberry varieties are provided in Table 1.

Table 1. Influence of the mineral composition of the growing medium on the garden strawberry multiplication coefficient, pcs/explant

\begin{tabular}{|c|c|c|c|c|c|c|}
\hline \multirow{2}{*}{ Variety } & \multirow{2}{*}{$\begin{array}{l}\text { Growing } \\
\text { medium }\end{array}$} & \multicolumn{4}{|c|}{ Passage number } & \multirow{2}{*}{$\begin{array}{c}\text { Average } \\
\text { per } \\
\text { passage }\end{array}$} \\
\hline & & 1 & 2 & 3 & 4 & \\
\hline \multirow{2}{*}{ Bereginya } & MS & $1.8 \pm 0.2$ & $2.5 \pm 0.7$ & $2.0 \pm 0.3$ & $1.8 \pm 0.3$ & $2.0 \pm 0.4$ \\
\hline & Boxus - MS & $1.7 \pm 0.2$ & $2.0 \pm 0.2$ & $2.1 \pm 0.3$ & $2.0 \pm 0.3$ & $2.0 \pm 0.3$ \\
\hline \multirow{2}{*}{ Korona } & MS & $3.6 \pm 0.5$ & $1.5 \pm 0.2$ & $2.8 \pm 0.2$ & $2.9 \pm 0.5$ & $2.7 \pm 0.4$ \\
\hline & Boxus - MS & $3.1 \pm 0.3$ & $1.9 \pm 0.2$ & $1.4 \pm 0.2$ & $1.6 \pm 0.2$ & $2.0 \pm 0.2$ \\
\hline \multirow{2}{*}{ Marmolada } & MS & $1.6 \pm 0.2$ & $1.9 \pm 0.2$ & $2.7 \pm 0.4$ & $3.6 \pm 0.4$ & $2.5 \pm 0.3$ \\
\hline & Boxus - MS & $1.7 \pm 0.2$ & $1.6 \pm 0.2$ & $2.0 \pm 0.3$ & $1.9 \pm 0.2$ & $1.8 \pm 0.2$ \\
\hline \multirow{2}{*}{ Honeoye } & MS & $2.4 \pm 0.3$ & $1.8 \pm 0.2$ & $2.9 \pm 0.1$ & $2.9 \pm 0.5$ & $2.5 \pm 0.3$ \\
\hline & Boxus - MS & $2.6 \pm 0.6$ & $2.6 \pm 0.6$ & $2.3 \pm 0.3$ & $1.5 \pm 0.2$ & $2.2 \pm 0.4$ \\
\hline \multirow{2}{*}{ Tsaritsa } & MS & $2.3 \pm 0.4$ & $1.9 \pm 0.2$ & $3.2 \pm 0.3$ & $5.6 \pm 0.7$ & $3.3 \pm 0.4$ \\
\hline & Boxus - MS & $3.6 \pm 0.9$ & $2.5 \pm 0.3$ & $2.6 \pm 0.3$ & $2.3 \pm 0.3$ & $2.8 \pm 0.5$ \\
\hline \multirow{2}{*}{$\begin{array}{l}\text { Urozhaynaya } \\
\text { CGL }\end{array}$} & MS & $1.4 \pm 0.1$ & $2.7 \pm 0.3$ & $2.2 \pm 0.2$ & $4.0 \pm 0.4$ & $2.6 \pm 0.3$ \\
\hline & Boxus - MS & $1.9 \pm 0.5$ & $2.0 \pm 0.3$ & $2.2 \pm 0.3$ & $2.7 \pm 0.4$ & $2.2 \pm 0.4$ \\
\hline \multicolumn{2}{|l|}{$\mathrm{LSD}_{0.5}$} & & \\
\hline
\end{tabular}

In a comparative test of growing media, a greater number of additional micro-plants were obtained on the Murashige-Skoog basal growing medium containing 6-BAP $0.5 \mathrm{mg} / \mathrm{l}$. At the same time, the resulting plants, when extracted from the test tube, were brittle, often crumbled into separate parts, which is a sign of weak vitrification. The high concentration of ammonium and nitrate nitrogen in the Murashige-Skoog growing medium is the main reason for plants hydration in the artificial growing medium [22]. The exclusion of ammonium nitrate $\left(\mathrm{NH}_{4} \mathrm{NO}_{3}\right)$ and replacement of calcium chloride $\left(\mathrm{CaCl}_{2}\right)$ with calcium nitrate $\left(\mathrm{Ca}\left(\mathrm{NO}_{3}\right)_{2}\right)$ in the Boxus nutrient medium in strawberry provided obtaining optimally developed strawberry plants. When the Boxus growing medium alternated with the non-hormonal MS medium, no signs of vitrification were observed, the plants remained intact and strong, and had a large height, which is an important factor for the transition to the rooting stage. The results are shown in Table 2

Table 2. Influence of growing medium mineral composition on the height of strawberry micro-plants, $\mathrm{mm}$

\begin{tabular}{|c|c|c|c|c|c|c|}
\hline \multirow{2}{*}{ Variety } & \multirow{2}{*}{$\begin{array}{l}\text { Growing } \\
\text { medium }\end{array}$} & \multicolumn{4}{|c|}{ Passage number } & \multirow{2}{*}{$\begin{array}{c}\text { Average } \\
\text { per passage }\end{array}$} \\
\hline & & 1 & 2 & 3 & 4 & \\
\hline \multirow{2}{*}{ Bereginya } & MS & $7.2 \pm 0.3$ & $11.2 \pm 0.9$ & $9.8 \pm 0.2$ & $8.4 \pm 0.9$ & $9.2 \pm 0.6$ \\
\hline & Boxus - MS & $11.5 \pm 0.6$ & $10.7 \pm 0.8$ & $10.6 \pm 0.8$ & $13.8 \pm 0.9$ & $11.7 \pm 0.8$ \\
\hline \multirow{2}{*}{ Korona } & MS & $10.0 \pm 0.5$ & $10.9 \pm 0.8$ & $9.8 \pm 0.7$ & $13.4 \pm 0.8$ & $11.0 \pm 0.7$ \\
\hline & Boxus - MS & $12.3 \pm 0.6$ & $11.4 \pm 0.7$ & $13.4 \pm 0.9$ & $10.9 \pm 0.8$ & $12.0 \pm 0.8$ \\
\hline \multirow{2}{*}{ Marmolada } & MS & $11.2 \pm 0.5$ & $10.8 \pm 0.9$ & $8.1 \pm 0.6$ & $9.3 \pm 0.7$ & $9.9 \pm 0.7$ \\
\hline & Boxus - MS & $10.5 \pm 0.8$ & $9.3 \pm 0.6$ & $12.7 \pm 0.7$ & $10.6 \pm 0.6$ & $10.8 \pm 0.7$ \\
\hline \multirow{2}{*}{ Honeoye } & MS & $8.7 \pm 0.4$ & $8.8 \pm 0.4$ & $8.0 \pm 0.3$ & $12.2 \pm 0.9$ & $9.4 \pm 0.5$ \\
\hline & Boxus - MS & $9.4 \pm 0.5$ & $10.5 \pm 0.7$ & $9.4 \pm 0.8$ & $10.0 \pm 0.7$ & $9.8 \pm 0.7$ \\
\hline \multirow{2}{*}{ Tsaritsa } & MS & $8.1 \pm 0.6$ & $10.5 \pm 0.9$ & $7.5 \pm 0.4$ & $8.7 \pm 0.6$ & $8.7 \pm 0.6$ \\
\hline & Boxus - MS & $10.5 \pm 0.9$ & $10.6 \pm 0.7$ & $9.8 \pm 0.6$ & $9.8 \pm 0.5$ & $10.2 \pm 0.7$ \\
\hline \multirow{2}{*}{$\begin{array}{l}\text { Urozhaynaya } \\
\text { CGL }\end{array}$} & MS & $12.1 \pm 0.7$ & $10.6 \pm 0.7$ & $8.9 \pm 0.9$ & $8.1 \pm 0.8$ & $9.9 \pm 0.8$ \\
\hline & Boxus - MS & $11.6 \pm 0.7$ & $10.3 \pm 0.7$ & $9.6 \pm 0.8$ & $9.5 \pm 0.6$ & $10.3 \pm 0.7$ \\
\hline \multicolumn{2}{|l|}{$\mathrm{LSD}_{05}$} & \multicolumn{4}{|c|}{2.0} & \\
\hline
\end{tabular}

On average, in varieties, a greater number of micro-plants suitable for rooting were obtained using media alternating method, as can be seen from table 3 . 
Table 3. The proportion of strawberry shoots over $5 \mathrm{~mm}$, on average per passage, $\%$

\begin{tabular}{|l|l|l|l|l|l|l|}
\hline $\begin{array}{l}\text { Growing } \\
\text { medium }\end{array}$ & Bereginya & Korona & Marmolada & Honeoye & Tsaritsa & $\begin{array}{c}\text { Urozhaynaya } \\
\text { CGL }\end{array}$ \\
\hline MS & 66.6 & 74.4 & 64.7 & 58.6 & 67.5 & 53.6 \\
\hline $\begin{array}{l}\text { Boxus - } \\
\text { MS }\end{array}$ & 83.0 & 86.4 & 81.4 & 63.3 & 70.0 & 77.5 \\
\hline
\end{tabular}

\subsection{Blackberry}

Micro-shoots were planted on growing media with a mineral base according to MurashigeSkoog, Ly de Fossard and Gamborg, using 6-BAP at a concentration of $1.0 \mathrm{mg} / \mathrm{l}$ as an inducer of additional shoots proliferation. According to N.V. Solovykh [23], this concentration is optimal for blackberry explants development.

As noted in the works of other researchers [24], the processes of proliferation and development of cultivated micro-shoots depend on the variety-specific response of each genotype to the mineral composition of growing media, which is confirmed by our studies. The greatest proliferative activity was observed in the seedling of the Black Satin and Eri varieties. The breeding process was active on the Ly Fossard medium. This medium also contributed to the increase in the multiplication coefficient of the Thornfree and Agawam varieties. The formation of a larger number of well-developed shoots was noted, which is reflected in Table 4.

Table 4. Influence of the growing medium composition on the blackberry varieties proliferation

\begin{tabular}{|c|c|c|c|}
\hline $\begin{array}{l}\text { Variety } \\
\text { (factor } \\
\text { A) } \\
\end{array}$ & $\begin{array}{c}\text { Growing medium (factor } \\
\text { B) }\end{array}$ & $\begin{array}{l}\text { Multiplication } \\
\text { coefficient, } \\
\text { pcs/explant } \\
\end{array}$ & $\begin{array}{c}\text { Shoots proportion with } \\
\text { a length of } 5 \mathrm{~mm} \text { or } \\
\text { more, } \% \\
\end{array}$ \\
\hline \multirow{3}{*}{ Thornfree } & MS & $4.0 \pm 0.3$ & 51.6 \\
\hline & Ly de Fossard & $5.0 \pm 0.4$ & 40.8 \\
\hline & Gamborg & $4.4 \pm 0.4$ & 56.1 \\
\hline \multirow{3}{*}{ Agawam } & MS & $4.3 \pm 0.4$ & 31.8 \\
\hline & Ly de Fossard & $4.8 \pm 0.4$ & 39.0 \\
\hline & Gamborg & $4.0 \pm 0.4$ & 39.0 \\
\hline \multirow{3}{*}{$\begin{array}{l}\text { Seedling } \\
\text { Black } \\
\text { Satin }\end{array}$} & MS & $4.4 \pm 0.4$ & 35.5 \\
\hline & Ly de Fossard & $6.1 \pm 0.5$ & 48.0 \\
\hline & Gamborg & $5.1 \pm 0.5$ & 46.2 \\
\hline \multirow{3}{*}{ Eri } & MS & $5.7 \pm 0.4$ & 26.5 \\
\hline & Ly de Fossard & $5.2 \pm 0.4$ & 52.5 \\
\hline & Gamborg & $4.5 \pm 0.4$ & 44.6 \\
\hline \multicolumn{2}{|r|}{$\mathrm{LSD}_{0.5}$} & 1.14 & 1.14 \\
\hline
\end{tabular}

Depending on the studied variety and the growing media composition, the conglomerates differed in the shoots number and length. The largest total number of shoots longer than $5 \mathrm{~mm}$ was formed in the Thornfree variety, the smallest - in the Agawam variety.

The result of variance analysis revealed a significant impact of genotype (factor A) and type of growing medium (factor B) on the multiplication coefficient and number of shoots from $5 \mathrm{~mm}$ and more, joint effect of these factors is not reliably established.

\subsection{Pear}

A comparative study of the growing media most often recommended for fruit crops showed the advantage of the Murashige-Skoog and Ly de Fossard media. Cultivation of pear 
explants on these media provided rapid formation of lateral shoots and buds, and shoots elongation. Nevertheless, after 4 weeks of cultivation, tissue necrosis began in the formed conglomerates on the Ly de Fossard growing medium, and vitrification in some regenerants. This feature was shown in all varieties with the exception of the Lada variety. In this variety, the largest number of micro-shoots of more than $5 \mathrm{~mm}$ was formed on the Ly de Fossard medium. Weak conglomerate development and growth of wound callus were observed in most varieties on the Pierik growing medium.

The most active processes of proliferation and shoot growth in length were in the Tyutchevskaya variety. Orlovskaya Letnyaya variety had low regenerative potential.

The results of the study are shown in Table 5.

Table 5. Influence of growing media mineral composition on the pear varieties proliferation

\begin{tabular}{|c|c|c|c|}
\hline $\begin{array}{c}\text { Variety } \\
\text { (factor } \\
\text { A) }\end{array}$ & $\begin{array}{c}\text { Growing medium } \\
\text { (factor B) }\end{array}$ & $\begin{array}{c}\text { Multiplication } \\
\text { coefficient, } \\
\text { pcs/explant }\end{array}$ & $\begin{array}{c}\text { Shoots proportion with a } \\
\text { length of 5 mm or more, } \\
\text { \% }\end{array}$ \\
\hline \multirow{4}{*}{$\begin{array}{c}\text { Tyutchev } \\
\text { skaya }\end{array}$} & MS & $6.2 \pm 0.5$ & 51.6 \\
\cline { 2 - 4 } & Ly de Fossard & $6.7 \pm 0.6$ & 54.2 \\
\cline { 2 - 4 } & Gamborg & $4.4 \pm 0.4$ & 53.6 \\
\hline \multirow{4}{*}{ Lada } & Pierik & $5.1 \pm 0.6$ & 26.6 \\
\cline { 2 - 4 } & MS & $4.3 \pm 0.4$ & 36.2 \\
\cline { 2 - 4 } & Ly de Fossard & $4.8 \pm 0.4$ & 73.2 \\
\cline { 2 - 4 } & Gamborg & $4.0 \pm 0.4$ & 53.4 \\
\hline \multirow{3}{*}{$\begin{array}{c}\text { Orlovska } \\
\text { ya }\end{array}$} & Pierik & $1.3 \pm 0.1$ & 43.3 \\
\cline { 2 - 4 } & MS & $4.4 \pm 0.4$ & 32.2 \\
\cline { 2 - 4 } & Gamborg & $6.1 \pm 0.5$ & 16.8 \\
\hline \multirow{3}{*}{$\begin{array}{c}\text { Annushk } \\
\text { a }\end{array}$} & Pierik & $5.1 \pm 0.5$ & 14.1 \\
\cline { 2 - 4 } & Ly de Fossard & $1.9 \pm 0.1$ & 5.6 \\
\cline { 2 - 4 } & Gamborg & $5.7 \pm 0.4$ & 47.1 \\
\cline { 2 - 4 } & Pierik & $4.2 \pm 0.4$ & 41.0 \\
\hline & LSD & $3.8 \pm 0.4$ & 29.0 \\
\hline
\end{tabular}

Evaluating the growth regulators effect on the formation of additional pear microshoots, it was found that 6-BAP has the greatest activity at a concentration of $2.0 \mathrm{mg} / \mathrm{l}$. An increase in the content of 6-BAP from $0.5 \mathrm{mg} / 1$ to $2.0 \mathrm{mg} / 1$ contributed to an increase in the multiplication coefficient by 1.5-2 times. Increasing the cytokinin concentration to $3.0 \mathrm{mg} / \mathrm{l}$ reduced the proliferative activity. The data obtained are shown in Figure 1.

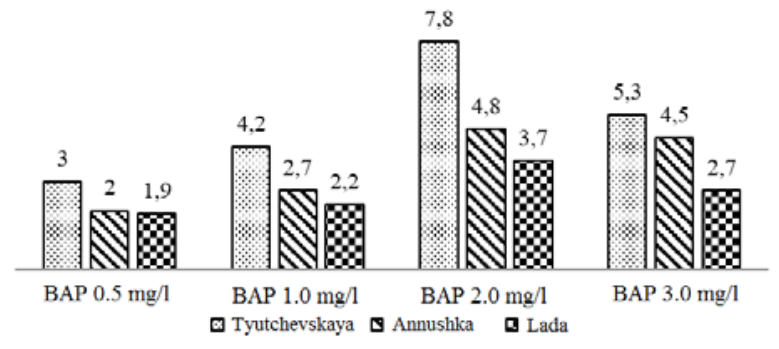

Fig. 1. Effect of 6-BAP concentrations on the multiplication coefficient of pear varieties

\subsection{Apple tree}

During clonal micro-reproduction of apple tree varieties genotype-dependence is often traced, which is due to the high heterozygosity of the genus Malus [14, 25]. Many 
genotypes can be propagated on a single medium, however, there are varieties that require the development of an individual cultivation scheme [26]. That is why we used several variants of growing media in combination with 6-BAP cytokinin.

Observations of the reproduction and morpho biological state of micro-plants showed that the Bolotovskoye variety had the highest proliferative activity on the QL growing medium with the addition of 6-BAP $2.0 \mathrm{mg} / \mathrm{l}$, and the longest shoot length on the Fardzinova medium.

In the Imrus variety, the obtained development indicators on both media were practically the same, but on the QL medium with the addition of 6-BAP at a concentration of $2.0 \mathrm{mg} / 1$ vitrification of $50 \%$ of shoots was observed. For the Kandil Orlovsky and Orlovskoye Polesye varieties the QL medium was the most favorable. The Veteran variety was characterized by a low multiplication coefficient on the QL medium, but active growth in length was observed. The degree of shoots proliferation on Fardzinova medium could be increased 1.5-2 times. The results of the study are shown in Table 6.

Table 6. Influence of growing media mineral composition on the apple tree varieties proliferation

\begin{tabular}{|c|c|c|c|c|c|}
\hline \multirow{2}{*}{$\begin{array}{c}\text { Variety } \\
\text { (factor A) }\end{array}$} & $\begin{array}{c}\text { Concentration } \\
\text { 6-BAP }\end{array}$ & $\begin{array}{c}\text { Multiplication } \\
\text { coefficient, } \\
\text { pcs/explant }\end{array}$ & $\begin{array}{c}\text { Qhoots } \\
\text { proportion } \\
\text { with a length } \\
\text { of 5 mm or } \\
\text { more, } \%\end{array}$ & $\begin{array}{c}\text { Fardzinova (factor B) } \\
\text { Multiplication } \\
\text { coefficient, } \\
\text { pcs/explant }\end{array}$ & $\begin{array}{c}\text { Shoots } \\
\text { proportion } \\
\text { with a length } \\
\text { of 5 mm or } \\
\text { more, } \%\end{array}$ \\
\hline \multirow{2}{*}{$\begin{array}{c}\text { Kandil } \\
\text { Orlovsky }\end{array}$} & $1.0 \mathrm{mg} / 1$ & $2.9 \pm 0.4$ & 68.4 & $1.8 \pm 0.1$ & 72.9 \\
\cline { 2 - 6 } & $2.0 \mathrm{mg} / 1$ & $3.4 \pm 0.3$ & 64.6 & - & - \\
\hline \multirow{2}{*}{ Imrus } & $1.0 \mathrm{mg} / 1$ & $2.3 \pm 0.2$ & 61.2 & $3.3 \pm 0.3$ & 62.0 \\
\hline \multirow{2}{*}{$\begin{array}{c}\text { Orlovskoye } \\
\text { Polesie }\end{array}$} & $2.0 \mathrm{mg} / 1$ & $2.1 \pm 0.2$ & 75.2 & $2.3 \pm 0.3$ & 65.4 \\
\cline { 2 - 6 } Bolotovskoye & $1.0 \mathrm{mg} / 1$ & $2.3 \pm 0.2$ & 81.3 & $1.4 \pm 0.1$ & 87.6 \\
\cline { 2 - 6 } & $1.0 \mathrm{mg} / 1$ & $2.9 \pm 0.2$ & 75.7 & - & - \\
\hline \multirow{2}{*}{ Veteran } & $2.0 \mathrm{mg} / 1$ & $3.0 \pm 0.3$ & 70.2 & $2.7 \pm 0.2$ & 80.6 \\
\cline { 2 - 6 } & $1.0 \mathrm{mg} / 1$ & $4.5 \pm 0.9$ & 61.5 & $3.3 \pm 0.3$ & 73.6 \\
\hline \multicolumn{2}{|c|}{$2.0 \mathrm{mg} / 1$} & $1.9 \pm 0.1$ & 88.9 & $2.4 \pm 0.2$ & 57.3 \\
\hline
\end{tabular}

During the variance analysis, the reliability of genotype effect on the proliferation degree and the shoots elongation on both media was established. Genotype and concentrations of 6-BAP in the Fardzinova medium influenced equally. On this medium, a decrease in the multiplication coefficient was observed in most of the varieties studied by us.

Thus, the Quoirin-Lepoivre growing medium was more favorable for the cultivation of apple tree micro-shoots. The cytokinin concentration should be selected individually for each variety.

\section{Conclusions}

The results of the studies showed the dependence of proliferative activity and development of micro-shoots of the studied crops on the genotypic features of each variety. Varieties that can be cultivated using a common technique were identified, as well as individual genotypes requiring an individual approach.

To avoid vitrification of strawberry micro-plants, it is recommended to use alternating growing media: Boxus (6-BAP-1.0 mg/l) and non-hormonal medium MS.

For blackberry and pear varieties, the most effective is the Ly de Fossard growing medium. 
The optimal growing medium for the apple varieties cultivation is Quoirin-Lepoivre growing medium. To increase the multiplication coefficient, it is recommended to use 6BAP at a concentration of $2.0 \mathrm{mg} / \mathrm{l}$. For the Veteran variety, it is recommended to use the Fardzinova growing medium.

The results obtained can be used to develop systems for the production of healthy planting material of the studied crops using biotechnological approaches.

\section{References}

1. L.L. Buntsevich, M.A. Vinter, Agricultural Bulletin of Stavropol Region, 2(26), 177 (2017)

2. Yu.V. Trunov, A.V. Solovyov, I.I. Kozlova, S.A. Muratova, Technology of growing high-quality planting material of fruit and berry plants, 246 (2018)

3. D.Z. Bogoutdinov, T.B. Kastalyeva. N.V. Girsova, L.N. Samsonova, Agrobiology, 1(54), 3 (2019)

4. S.E. Dunaeva, Yu.S. Osledkin, Agricultural Biology, 50(1), 3 (2015)

5. I. Sowik, A. Bielenin, I. Michalczuk, Sci. Hort., 88, 31 (2001)

6. I.V. Mitrofanova, O.V. Mitrofanova, N.P. Lesnicova-Sedoshenko, S.V. Chelombit, Y.M. Gorina, S.N. Chirkov, Acta Horticulturae, 1290, 237 (2020)

7. J.I. Zebrowsca, J. Czemas, J. Gawronski, J.A. Hortynski, Food, Agriculture \& Environment, 1, 190 (2003)

8. A. Kikas, A. Libek, Acta Horticulturae, 708, 241 (2006)

9. I. Kozlova, Pomiculture and small fruits culture in Russia, 38(1), 200 (2014)

10. O.V. Matushkina, I.N. Pronina, Breeding and variety culture of fruit and berry crops, 6(1), 74(2019)

11. L.A. Gruner, B.B. Kornilov, Vavilov Journal of Genetics and Breeding, 24(5), 489 (2020)

12. E.N. Sedov, G.A. Sedysheva, Z.M. Serova, T.V. Yanchuk, Our agriculture, 1(225), 110 (2020)

13. N.V. Kukharchik, M.S. Kastritskaya, S.E. Semenas, E.V. Kolbanova, T.A. Krasinskaya, N.N. Volosevich, O.V. Solovey, A.A. Zmushko, T.N. Bozhiday, A.P. Rundya, A.M. Malinovskaya, Reproduction of fruit plants in culture in vitro, 208 (2016)

14. O.V. Matushkina, I.N. Pronina, Technology of clonal micropropagation of apple and pear trees, 32 (2008)

15. E.N. Dzhigadlo, M.I. Dzhigadlo, L.V. Galyshkina, Methodological recommendations on the use of biotechnological methods in working with fruit, berry and decorative crops, 51 (2005)

16. T. Murashige, F. Scoog, Physiol. Plant, 15(3), 493 (1962)

17. P. Boxus, J. Hortic. Sci., 49, 209 (1974)

18. R.A. Fossard, R.A. Bourne, Tissue culture for horticultural purposes. Acta Hort., 78, 37 (1977)

19. O.L. Gamborg, D.E. Eveleigh, Can. J. Biochem., 46(5), 417 (1968)

20. R. Pierik, A. Post, Sci Hortic., 3(3), 293 (1975)

21. M. Quorin, P. Lepoivre, Acta Hortic, 78(4), 437 (1977) 
22. O.V. Matushkina, I.N. Pronina, Main results and prospects of scientific research at VNIIS named after Michurin, 103 (2001)

23. N.V. Solovych, Pomiculture and small fruits culture in Russia, 37(1), 316 (2013)

24. D.N. Skovorodnikov, N.V. Melekhina, Yu.N. Orlova, The Bryansk State University Herald, 3, 417 (2015)

25. J. Dobránszki, J.A. Teixeira da Silva, Biotechnology Advances, 28(4), 462 (2010)

26. B. Kabylbekova, I. Kovalchuk, Z. Mukhitdinova, T. Turdiyev., G. Kairova, G. Madiyeva, \& B.M. Reed, In Vitro Cellular \& Developmental Biology-Plant, 1 (2020) 